ano 15

n. 31

palavras-chave:

Minimalismo; arte contemporânea; instituições de arte

keywords: Minimalism; Contemporary Art; art institutions

1. Tradução de Lara Rivetti

*Artista visual.

DOI: 10.11606/issn.2178-0447. ars.2017.140397.

\section{Tamanho é documento}

\section{Size matters.}

Este texto, publicado na revista Critical Inquiry, em 2000, aborda as relações entre o Minimalismo e a arte contemporânea. $\mathrm{O}$ autor propõe a análise daquilo que entende como uma retórica da Arte Minimalista, vinculada a uma ideologia da pureza do espaço e da forma e a uma noção de transcendência que encontram seus antecedentes, em parte, no Puritanismo. Morris investiga como esse discurso, articulado a um contexto social e a uma configuração dos espaços públicos nos quais predomina a ideia da vida como lifestyle, contribui para que a produção artística e a atuação dos museus e instituições de arte, a partir sobretudo dos anos 1990, se aproximem cada vez mais da noção de arte enquanto entretenimento.

This text, published on journal Critical Inquiry, in 2000, addresses the relations between Minimalism and contemporary art. The author suggests the analysis of what he understands as a rhetoric of Minimalist Art, linked to an ideology of space and shape purity and to a notion of transcendence that meets its antecessors, partly, in Puritanism. Morris investigates how this discourse, allied to a social context and to a configuration of public space in which prevails the idea of life as a lifestyle, contributes so that the artistic production and the museums' and art institutes' actions, especially as of the nineties, get increasingly closer to the notion of art as entertainment. 
Tao que pode ser ensinado

Não é o Tao eterno.

O nome que pode ser falado

Não é o nome eterno.

"Não-ser" é a origem do Céu e da Terra.

'Ser'é a mãe de todas as coisas.

Assim, o caminho do não-ser

conduz à contemplação do milagre da essência,

o caminho do ser,

à contemplação dos espaços em seus limites.

Lao Tse, Tao Te Ching: o livro do caminho e da virtude
210

Robert Morris

Tamanho é documento. (n)

A cidade dos anos 1960 ainda era um ambiente principalmente utilitário. A estetização dos espaços urbanos que ocorreu nos anos 1990 representa uma transformação radical. A própria noção de lifestyle - ainda inconcebível na década de 1960 - é um conceito estético e atesta por si só a transformação ocorrida na vida urbana. Esta também se confirma na conversão de bairros outrora utilitários, como SoHo e Chelsea, na cidade de Nova Iorque, em guetos culturais um degrau acima dos parques temáticos. Com a chegada dos anos 1990, o entretenimento adquiriu a forma, nessas áreas, de uma espécie de centro comercial de cultura, que começou com algumas poucas galerias de arte e logo se transformou em sofisticados imóveis de alto padrão, lojas de artigos de luxo, espresso bars e restaurantes de primeira. Há trinta e cinco anos, era possível viver tranquilamente e de modo marginal em Nova Iorque, sobreviver com um emprego de meio-período e ter bastante tempo livre para ocupações intelectuais ou artísticas. Hoje em dia, não existe margem na vida da cidade grande. O estético se tornou uma franquia e foi incorporado em cada item de troca. Mas afirmar, como Pierre Bourdieu, que o estético é apenas mais um item de consumo, uma mera marca de classe, significa perder de vista o modo ubíquo com que este invadiu e transformou a vida urbana ${ }^{2}$. Também eram inexistentes, nos anos 1960, o espaço da informação e um colorido e multifacetado ciberespaço a serviço de todo e qualquer comichão humano, no qual subgrupos de interesses especializados multiplicam-se e se desdobram em múltiplos sub-subgrupos com a velocidade de fractais de Mandelbrot. Se o corpo, com seus piercings e tatuagens, já se tornou a tela, como deveria a arte confrontar um corpo já apresentado enquanto arte? Que papel pode a arte desempenhar em um cenário no qual a elaboração autoconscien-

2. Cf. BOURDIEU, Pierre. Distinction: a social critique of the judgment of taste. Tradução Richard Nice. Cambridge, MA: Harvard University Press, 1984; Idem. A distinção: crítica social do julgamento. Tradução Daniela Kern e Guilherme Teixeira. Porto Alegre: Zouk, 2007. te de um lifestyle já determina um espaço estético ao redor do corpo? 
ARS Mesmo sendo, atualmente, os valores do entretenimento e da moda os

ano 15

ก. 31

3. BÍBLIA. A. T.

Deuteronômio 5: 8. Tradução João Ferreira de Almeida. [s.l., s.n.], 1994, p. 313.

4. Cf. BARR, Alfred. Cubism and abstract art: painting, sculpture, constructions, photography, architecture, industrial art, theatre, films, posters, typography. New York: Museum of Modern Art, 1936; Idem. Cubism and abstract art: painting, sculpture, constructions, photography, architecture, industrial art, theatre, films, posters, typography. Cambridge, MA: The Belknap Press of Harvard University Press, 1986. que atuam como mediadores da fusão entre arte e vida, não estariam estes já estreitamente aproximados no acalorado contexto de uma arte anterior, mais elitista e autônoma? Se arte e vida se encontram, hoje em dia, unidas de modo sem precedentes, a questão que se coloca seria, então, sobre qual tipo de arte que se apresenta nessa fusão e qual tipo de vida se desenvolve em meio a uma nova saturação estética? O fato de que os anos 1990 parecem estar a anos-luz de distância da década de 1960 motiva um deslocamento do olhar em direção a uma arte específica surgida neste período, bem como ao seu legado, que persiste ainda no nosso tempo. Foi na penumbra de um espaço urbano cinzento e utilitário que a arte minimalista dos anos 1960 surgiu. De que contexto ela veio e quais eram seus valores?

As origens da arte abstrata se situam em um passado remoto na história do Ocidente. Proscrições iconoclastas contra a criação de imagens identificáveis remontam, pelo menos, ao segundo mandamento: "Não farás para ti imagem de escultura, nem semelhança alguma do que há em cima no céu, nem embaixo na terra, nem nas águas debaixo da terra" . A noção do sagrado na tradição judaico-cristã está intimamente relacionada a essas proibições iconofóbicas. E, evidentemente, a própria divindade deve permanecer irrepresentável, abstrata e sublime, para além da capacidade de concepção da mente humana.

A narrativa modernista Ocidental mais recente sobre um direcionamento progressivo, nas artes plásticas, rumo à abstração e à pureza da forma engloba os primeiros três quartos do século $\mathrm{XX}$ e já foi contada diversas vezes. Trata-se de uma narrativa dualista e contraditória que tem início, por um lado, com Kandinsky e as estórias de impulsos ora transcendentes, ora espirituais que teriam motivado a arte abstrata. A outra parte dessa ideologia, que se torna predominante em meados do século, é formada por um empirismo racionalista e formalista que reivindica a autonomia dos objetos abstratos. Com o decorrer do século, o projeto da arte abstrata continuava reverberando ecos do livro de Deuteronômio, ao mesmo tempo em que demandava, em alto e bom som, uma silenciosa e abstrata autonomia para a forma - doxologia formalizada por Alfred Barr já em 1936 -, isso sem contar a inevitabilidade histórica para ela reivindicada pouco tempo depois por Clement Greenberg ${ }^{4}$. Por volta da metade do século, uma arte abstrata defendida como uma espécie de empirismo do formalismo autossuficiente, um tipo de ontologia visual silenciosa, ao mesmo tempo motivada historicamente e concebida a partir de promessas de transcendência, assumiu um papel de destaque na cultura. 
Enquanto arte oficial, a abstração atingiu seu apogeu nos Estados Unidos nos anos 1950, com o surgimento do Expressionismo Abstrato. A retórica do Antigo Testamento de alguns dos artistas desse período - Barnett Newman, principalmente, mas Mark Rothko e Clyfford Still também podem ser incluídos nesse grupo - nos lembra novamente de como os apelos iconoclastas ao sagrado na arte abstrata ainda não haviam sido esquecidos. Se a arte abstrata atingiu certo estatuto clássico de arte elevada com o minimalismo dos anos 1960, a retórica de seus praticantes era declaradamente formal e secular em seus argumentos ideológicos. No entanto, eles haviam de fato esquecido Deus? Jonathan Edwards e Ralph Waldo Emerson haviam realmente desaparecido da arte americana? Será que as restrições da arte não objetiva - aquele mundo do iconoclasticamente não referencial, da imagem não mimética em que está ausente qualquer semelhança a algo reconhecível ainda refletiam uma afinidade com o Puritanismo e o transcendental?

De modo geral, admite-se que, mesmo ao se afastar de representações criadas por meio da semelhança, os trabalhos abstratos continuam sobejando referências contraditórias. A recusa à semelhança não garante nada além da satisfação de cumprir a cartilha da iconoclasta lei mosaica. De todo modo, como nos lembra Nelson Goodman, a semelhança é um critério fraco para a representação, já que qualquer coisa pode representar qualquer outra coisa. E, de modo inverso, não só um gêmeo não representa o outro, como traços de semelhança podem ser identificados em qualquer par de objetos do mundo ${ }^{5}$. Em oposição ao nominalismo e empirismo de Greenberg, todo objeto de arte se apresenta primeiro enquanto signo. Somente os signos são capazes de promover a experiência estética. Qualquer trabalho abstrato, assim como qualquer objeto de arte representacional, é interpretado em relação a esses antecedentes no seu subconjunto; essa leitura incontornavelmente histórica e simbólica define e orienta todas as obras de arte.

Qualquer trabalho abstrato pode ou não ter reivindicado para si o estatuto de um signo metafórico ou alegórico. Por sua vez, referências metonímicas se encontram ausentes, de modo geral, do sistema simbólico de trabalhos não objetivos - e quando nele se apresentam, costumam ser desqualificadas. Neste momento, cabe recordar a distinção estabelecida por Edmund Burke entre o belo e o sublime. Somente aquilo que é metafórico pode ascender ao estatuto do sublime, enquanto apenas o que é parcial, pequeno e, é claro, feminino (de acordo com Burke) pode ocupar a categoria do belo ${ }^{6}$. Na arte abstrata americana, aquilo que é grande não apenas é sempre melhor, como também é a única esperança diante daquele que é o seu oponente: o decorativo. Um Pollock pequeno
5. GOODMAN, Nelson. Languages of art: an approach to a theory of symbols. 2. ed. Indianapolis: Hackett, 1976, p. 4; Idem. Linguagens da arte: uma abordagem a uma teoria dos símbolos. Tradução Desiderio Murcho e Vitor Moura. Lisboa: Gradiva, 2006. (Coleção Filosofia aberta, v. 17).

6. BURKE, Edmund. A philosophical enquiry into the origin of our ideas of the sublime and beautiful. Oxford: Oxford University Press, 1990, p. 100, 103; Idem. Uma investigação filosófica sobre a origem de nossas ideias do sublime e do belo. Tradução Enid Abreu. Campinas: Unicamp; Papirus, 1993. 
ARS é reles decoração. Apenas os grandes signos têm uma chance nas meano 15 táforas masculinas do sublime. E, nos Estados Unidos, só aqueles que

n. 31 falam muito a sério. Nada de piadas, caretas ou palavras. A eliminação da representação e do verbal é também uma evidência da abertura para santificar um espaço estético que remonta aos silêncios do religioso. A habilidade singular de Ad Reinhardt de unir o irônico à austeridade elevada era recebida de forma custosa por seus colegas no final dos anos 1950. Como eles conceberiam suas protominimalistas Black Paintings, a sua recusa ao monumental, seu engajamento político e suas considerações como "A arte é algo sério demais para ser levado a sério"??

E seria possível que a ascensão da arte abstrata americana nos anos 1940 fosse tributária, em alguma medida, da Segunda Guerra Mundial? Uma ideologia que promovia a ênfase na arte como um fenomenalismo da experiência visual silenciosa, total e irredutivelmente coexistente ao objeto de arte (conforme o argumento de Greenberg) era a mesma que buscava afastar qualquer referência ao mundo exterior. Dentro de tal experiência, era possível se esquecer por alguns instantes do horror na Europa, que começava então a se intensificar em direção a uma tecnologia do extermínio que viria a distinguir aquele século como o mais sangrento até então.

A pintura abstrata gestual dos anos 1950 ecoava um pragmatismo, com destaque para o fazer e o know-how americano, não observado em momentos europeus antecedentes. Noções modernistas de progresso estavam implícitas à doutrina, isso sem falar das exortações emersonianas à autossuficiência. Mas as vagas evocações empíricas deweyanas à autonomia de uma experiência imediata e totalizante constituíam sua principal defesa. E essa defesa continuou a ser invocada na arte minimalista posterior - embora eu não me recorde de ter sido feita alguma menção ao nome de John Dewey. É apenas com a arte conceitual que a hegemonia do empirismo radical de Dewey (seu livro mais famoso era Arte como experiência) começa a ser questionada. A arte conceitual problematizava a hegemonia de uma experiência autônoma, nominalista e totalizante da arte. Não se tratava de importar reivindicações epistemológicas para a arte, mas sim de negar que a experiência empírica coincidia com o limite da arte. A arte conceitual, ao privilegiar a denominação e a descrição, assegurava a primazia da arte enquanto signo. Tratava-se de um movimento estratégico contra a ideologia que considerava o visual como uma presença autônoma e negava seu estatuto como signo. Evidentemente, a outra tradição, derivada em grande parte de Duchamp e que resultou na arte pop, nunca se deixou reduzir a uma posição ideológica tão restrita, mas o embate dialético da arte 
conceitual se dava com o empirismo da ideologia minimalista e ignorava a arte pop, considerada algo sobre o qual nem valia a pena se preocupar.

É com a arte minimalista que o conjunto de pressupostos do final do século XIX e início do XX reverberado por Dewey encontra sua viabilização. É nesse momento que a antiga religião do Puritanismo e do transcendentalismo, transplantada para estética da totalidade do pragmatismo deweyano, atinge sua plena síntese ideológica. Nesses trabalhos, um certo americanismo truculento encontra sua voz artística. Talvez se tratasse de uma voz um pouco áspera, mas que ainda lembrava os antigos cânticos.

A adaptação realizada pela arte minimalista de processos industriais, tornando-os manifestações de poder exercidas pela figura individual do artista, não apenas respondia aos clamores emersonianos por autossuficiência como também ampliava a convicção deweyana no fazer e em apelos insistentes e inabaláveis a uma acachapante, implacável experiência, ao mesmo tempo em que explorava o progressivo know-how tecnológico americano. A rejeição programática do minimalismo às tradições da arte europeia, compartilhada com os esforços mais ambiciosos do Expressionismo Abstrato, visava reprimir a memória e enfatizar a obsessão americana pelo novo e pelo presente, vistos como uma forma de progresso em relação a um passado que deveria ser esquecido. Foi Pollock, evidentemente, o primeiro a articular, com seu trabalho, essa ambição, instituindo um paradigma central. A arte minimalista tinha como objetivo apenas responder ao desafio proposto por Pollock e explorar aquilo que havia permanecido latente e pouco desenvolvido em sua obra - ou seja, expandir o holismo e a pureza, tornando-os uma prática comum. Se Pollock havia sido o profeta, o minimalismo era a congregação.

Os artistas minimalistas dos anos 1960 eram como os pioneiros da indústria, desbravando as fábricas e as usinas de aço. As obras deveriam carregar a marca do trabalho - ou seja, do trabalho masculino, o único trabalho sério possível, trazido ainda reluzente das fundições e usinas, sem nenhum pingo de ironia para arquear o seu hirto heroísmo. E o trabalho desses homens é grande, firme, sempre sensato, a priori. Como produzir um objeto que seja não objetivo? Algo que seja produzido como um objeto útil, potencialmente funcional, mas que é inutilizado, autônomo e inflexível. Molde, corte, dobre, curve; repita maquinalmente; e então largue-o. Largue esse objeto bem embaixo do seu nariz ou diante de seu corpo. A principal preocupação dessa empreitada - o risco de cair no decorativo, no feminino, no belo, em suma, no menor - só pode ser apaziguada pelo grande e pesado. Esse trabalho ia esmagar seu corpo, ameaçar seu espaço e sua carne, te obrigar a 
transitar por entre sua concreta sublimidade. Esses trabalhos eram tra-

ano 15

ก. 31
8. EDWARDS, Jonathan apud CRITTENDON, Charles. Democracy and capitalism. In: HONDERICH, Ted (ed.). The Oxford companion to philosophy. Oxford: Oxford University Press, 1995, p. 219.

9. SMITH, John; STOUT, Harry; MINKEMA, Kenneth (eds.).

A Jonathan Edwards reader. New Haven: Yale University Press, 1995, p. 10. balho. Do tipo que até mesmo aqueles antepassados da Nova Inglaterra, com suas mãos calejadas, teriam aprovado. Mas espere um pouco. Não seria esse zunido abaixo ou acima da retórica secular o murmúrio da transcendência pairando no ar?

Se Donald Judd recorreu a um rígido e reducionista empirismo deweyano, Robert Morris introduziu a gestalt das formas unitárias e a fenomenologia de Merleau-Ponty no debate, passando por cima da discreta e deweyana concepção da visão como algo distanciado em benefício de um engajamento corporal com o autorreflexivo. A conversão da experiência do óptico ao háptico, à percepção autorreflexiva do corpo de uma gestalt e de um espaço dualistas, passou a configurar o cerne formal da arte minimalista. Os objetos da arte minimalista ocupavam o mesmo espaço que você, exigindo que fossem confrontados tanto com o seu corpo quanto com a sua visão.

No entanto, o epicentro da obra de arte minimalista se situava acima de qualquer apelo declarado à experiência ou de uma recente fenomenologia materialista da noção de corpo de Merleau-Ponty, um corpo para o qual a percepção dependia do deslocamento, o que, portanto, conferia primazia ao espaço. Pois um mundo carregado paira acima de qualquer negociação do espaço incorporada por esses acachapantes objetos. E esse mundo é o mesmo que aquele, idealista e transcendente, pregado outrora pelo grande puritano Jonathan Edwards. Os escultores minimalistas mais severos (Carl Andre, Sol LeWitt, Morris, Dan Flavin no começo da carreira, o Richard Serra tardio) seguiam Edwards que, por sua vez, seguia a hierarquia estipulada por Locke ao considerar certos elementos, tais como a cor, enquanto características secundárias. Se esses elementos, vistos como não intrínsecos, eram reprimidos a fim trazer o háptico para o primeiro plano, onde "a solidez é mera resistência, a forma é a realização da resistência e o movimento é a transmissão da resistência de um espaço a outro", esses artistas jamais teriam declarado abertamente que "a resistência é nada mais do que o exercício do poder de Deus", mesmo que eles tenham promovido, assim como Edwards, a ascensão de valores formais a um estatuto moral ${ }^{8}$. Edwards já havia associado Deus ao espaço vazio com um discurso tão próximo da atitude grandiloquente adotada pelos minimalistas que chega a ser constrangedor: "mas eu coloquei em termos claros: até mesmo já afirmei que o espaço é deus”. Não é possível que exista o vazio, o nada mais absoluto fora da existência eterna do ser. Munido de uma iconografia puritana iconoclasta que condenava a representação, o que poderia ser melhor do que o aparente vazio do espaço para codificar o mais elevado valor estético? Um valor que, em seu 
inefável e carregado vazio, já aparentava ter se resfriado o suficiente para permitir que essa ideologia difusa se condensasse.

Evidentemente, nem toda arte minimalista fetichizou o espaço. Sem dúvida, o trabalho de Judd (e não é à toa que ele tenha sido um dos últimos aprendizes de Dewey), com sua ênfase em superfícies coloridas, como embalagens de doces, e em simplificados conjuntos seriais, deriva de uma posição essencialmente óptica. A fisicalidade do tato e incursões fenomenológicas ao espaço eram estranhas a esse trabalho. Aquela ânsia inquieta por uma transcendência radical de que estavam imbuídos os outros praticantes desse gênero, mais austeros, estava ausente daquelas pilhas de plástico e de chapas metálicas, infinitamente repetíveis, achatadas e essencialmente sem peso. Se a obra de Judd, que ele defendia nos termos de um empirismo radical, permanece sendo a mais secular e materialista entre os minimalistas, ela também é a mais decorativa. Permanentemente bela, mas nunca sublime, ela fetichizou o objeto enquanto ignorava o espaço.

Quanto aos outros artistas: a pureza do espaço e o grande como metáfora transcendental, senão do divino, pelo menos de algo inominável que habita um plano superior, erguem-se sobre um tipo viril e americano de know-how de baixa tecnologia como o suor que evapora de um honesto operário de fundição. A estética é promovida a uma moralidade da pureza. Deus está não nos detalhes, como pensava Mies van der Rohe, mas nos espaços entre eles. Estímulos à presença maciça do recorrente nesses trabalhos - repetições não apenas das subunidades que compõem uma obra, mas também a insistente produção de séries de trabalhos minimamente distintos entre si - jazem mais profundamente do que acomodações mercadológicas. Sobre essas repetições, paira algo de compulsivo próprio da oração. O acentuado formalismo do projeto da arte abstrata sempre apresentou uma atmosfera eclesiástica - a solenidade do fazer, a necessidade de um padre-crítico intercessor para esclarecer e dar a benção, a santidade do museu como local de adoração. O ruído estridente da primeira arte pop em coexistência com o minimalismo provocava irritação. Os artistas da arte pop estavam peidando na igreja.

A Land Art, surgindo no rastro do minimalismo, é inconcebível sem a doutrina minimalista do sublime, seu projeto de cooptação de processos industriais, sua insistência na clareza das formas gestálticas e a ênfase no primado do espaço. Mas, além desse programa formal, a Land Art retirou do minimalismo o desejo por uma tensa transcendência que, ao mesmo tempo em que assegurasse um rígido formalismo, impedisse ainda que o trabalho caísse no mero formalismo. A Land Art 
acrescentou um romantismo declarado a um programa minimalista.

ano 15

ก. 31

10. "What you see is what you get”, na versão original (N.T.).
Aquelas vastas áreas de natureza esculpida foram modificadas por uma temática emersoniana e passaram a reverberar um culto agrário à natureza que derivava, em parte, dos trabalhos de Frederick Law Olmsted. Mas aqueles acres de vivazes crepúsculos pintados por Thomas Cole e Frederick Church - espaços em que o paraíso de Deus teria descendido para tocar a terra - também devem ser considerados como antecedentes.

A arte minimalista representava a tentativa de recuperar valores puritanos transcendentes ao recodificá-los por meio de uma iconoclastia de austera pureza formal e espacial. Ao mesmo tempo, sua intenção era transpor e redimir processos industriais utilitários e formas gestálticas ao inseri-los no espaço estético do fenomenológico. Ecoando as ambições de William James, o minimalismo queria ter as duas coisas ao mesmo tempo: por um lado, o resoluto empirismo da declaração de Frank Stella de queo que você vê é exatamente o que você về ${ }^{10}$; por outro, a elusiva e idealista transcendência (que nunca fez parte da doxologia oficial) expressa na pureza das relações formais do espaço, cuja severidade quase legislatória implicava uma ordem transcendente que ia além do fenomenalismo estético. A severa ordenação espacial constituiu e codificou a relação transcendente - o espaço não era objetivo, nem apenas fenomênico; não era arbitrário, mas era mais do que somente racional; uma falta que sobrevinha o objeto físico com sua presença e generalidade. A força da arte minimalista residia na forma como ela sustentava essa relação paradoxal, como o espaço rigorosamente ordenado da ausência tornava a gestalt do objeto mais real, como o tangível era interpretado por meio do intangível, dando origem à percepção das relações entre objetos ancorados em um prescritivo espaço transcendente. $\mathrm{O}$ espaço se revela no comportamento do objeto, mas ele próprio não se constitui como um objeto atuante. A ambição desse trabalho é evidenciada, como em qualquer arte vital, por meio das engenhosas estratégias usadas para confrontar suas contradições e mantê-las em uma tensa suspensão. E, como em toda arte vital, as tensões incorporadas nessa encenação não poderiam durar. E, como em toda arte vital, a arte minimalista não escapou de uma persistente e residual fase maneirista, como é o caso do trabalho mais recente de Serra. Essas obras, que se aproximam da tonelagem de porta-aviões para dar força a uma debilitada fenomenologia da experiência, na tentativa de mantê-la flutuando, naufragam, contudo, ao nível de ícones deslocados que evocam imagens de um intumescido poder corporativo - uma acusação que não poderia ter sido apontada no trabalho minimalista dos anos 
1960, quando suas contradições inerentes eram mantidas em um tenso equilíbrio e o gigantismo era desnecessário.

A arte minimalista, no seu auge durante a década de 1960, era uma espécie de arte religiosa. Desinvestida, talvez, de seu estatuto eclesiástico, mas ainda religiosa ao manter sua transcendência suspensa naqueles espaços imateriais que permeavam suas densidades formais. Ela encapsulou e retomou uma reformulação tipicamente americana do pensamento material do fazer artístico. Esse pensamento material remava a favor de, e não contra a corrente histórica constituída pela tríplice tradição americana do Puritanismo, do transcendental e do pragmático. Sua contribuição foi utilizar Pollock como base para criar metáforas para esses duradouros valores (valores que até os anos 1990 não estavam perto de desaparecer) por meio de uma experiência estética purificada - uma experiência que soldava formas e processos utilitários a imagens iconofóbicas, permitindo que o próprio espaço reafirmasse aquela esquecida ou reprimida garantia transcendente reivindicada para ele pelo maior de todos os puritanos, Johathan Edwards ${ }^{11}$.

$$
* * *
$$

Mas, à medida que os anos 1990 terminam, encontra-se essa antiga tripla tradição americana definitivamente encerrada? Certamente, pelo menos uma versão jamesiana mais crua de um pragmatismo sancionando relativismos e oportunismo ainda se mantém atuante. E as questões de Edwards? Estão enterradas embaixo da tonelagem arrebatadora do entretenimento? No entanto, no meio de um espaço urbano carregado, cheirando a um estetizado ambiente material, ainda é possível detectar o mais débil dos calafrios de culpa puritana? E onde deveriam ser registrados tais abalos sísmicos da psique? Na arte? É possível que exista uma arte que ofereça alguma espécie de promessa de redenção aos assaltos de todas essas material girls? Em sua maioria, estes não representam celebrações da atordoada efervescência da ironia enquanto lifestyle?

Mas espere um pouco. E quanto a uma arte realmente grande? Grande o bastante para ser escutada entre risadas culpadas e para se erguer muito acima dos ombros desses preguiçosos inúteis. Tão grande que nos leva a imaginar o quanto deve ter custado, mesmo em um tempo em que o dinheiro está fora de controle. E pode se esquecer do abstrato. Quem ainda se importa? A profusão de imagens dos anos 1990 nivela, anestesia e equaliza; uma imagem é tão boa quanto outra. Grande é o que importa. Grande não é tudo, mas talvez seja a única
11. Em seu ensaio de 1967, "Arte e objetidade", um texto que toma meu trabalho como o ponto central para seu ataque à "teatralidade", Michael Fried se concentra mais nos objetos da escultura minimalista e menos no espaço quando repreende o "literalismo" a que eles teriam se reduzido. Cf. FRIED, Michael. Art and objecthood. In:___. Art and objecthood: essays and reviews. Chicago: University of Chicago Press, 1998, p. 154,168 . Fried cita Edwards na epígrafe desse ensaio. Não há dúvidas de que ele consideraria os usos que fiz de Edwards neste texto como uma evidência clara de apostasia. Em retrospecto, a única falha que encontro no ensaio de Fried é que ele não estendeu o conceito de teatralidade o suficiente. 
coisa que possa ser notada. A única coisa capaz de competir com o baano 15

12. Além dessas marcas óbvias do romântico - as preocupações com culpa e redenção, origens e misticismo -, incluo ainda as contribuições particulares de Wagner: as noções de eternidade e grande escala, o encanto atordoante, a monotonia do repetitivo, 0 peso e o caráter portentoso do mais uma vez reformulado sublime, o espírito "prepare-se que aí vou eu" do agressivamente teatral - em suma, tudo aquilo le um pouco mais) que Nietzsche viria a detestar e a considerar decadente no trabalho de Wagner. Cf. NIETZSCHE, Friedrich. The case of Wagner. In: The birth of Tragedy and the case of Wagner. Tradução Walter Kaufmann. New York: Vintage, 1967, p. 155-192. rulho do estilo com seu rugido de manifestações ubíquas e mutantes.

Se o efeito Mozart deve ser percebido em relação ao grão daquele ruído entorpecente, talvez haja algo que possa ser chamado de efeito Wagner atuando em outra direção, representando, quem sabe, um movimento contrário ou, em todo caso, algo que ainda precise ser teorizado. $\mathrm{O}$ efeito Wagner estaria ligado a esses iminentes ícones de uma presença soberana, oferecendo um tipo peculiar de perdão secretamente dirigido àqueles cujas existências culposas tornam tais expressões possíveis. $\mathrm{O}$ trabalho incluído sob a rubrica do efeito Wagner estaria a serviço dos altos escalões daquela que seria uma classe dominante que, em sua generosidade calculada, reivindica os vastos e santificados espaços do museu como testemunho da importância de sua classe e de seu autocomplacente serviço público. Um tipo de arte que é dura até mesmo para entrar no museu. Maciça, de difícil manuseio, perturbadoramente cara e wagneriana até seu cerne, cujo valor por si só já configura uma espécie de garantia de redenção, sustentando a promessa de uma transcendência mais nebulosa e embolorada do que Edwards jamais poderia suportar. Iluminada por um baço e sombrio céu romântico, a arte que exala o efeito Wagner talvez emburreça (em oposição ao efeito Mozart, que torna até ratos mais espertos) ou anestesie com um massivo, atordoante e místico encanto estético cujo valor por metro quadrado já é capaz de causar vertigem. Estilo não importa muito para o efeito Wagner, sua força motriz está no tamanho agigantado e no valor elevado das obras. Evidentemente, além da grandiosidade, toques de misticismo e alusões a uma origem também não machucam - pelo menos não machucaram Wagner ${ }^{12}$.

Quando Anselm Kiefer realiza suas pinturas com o uso de espátulas sobre acres de sangue e terra, ele está, sem dúvida, bebendo da fonte do efeito Wagner. Mas desde os mais amplos gestos, remontando ao Expressionismo Abstrato - passando por Robert Wilson, Roy Lichtenstein e Chuck Close, até os trabalhos de artistas da Land Art como Michael Heizer, cuja obra Cidade, no deserto, é certamente um dos mais monstruosos e significativos exemplos do gênero produzidos neste século, e sem esquecer os trabalhos dos herdeiros da Land Art, como o Monumento aos Veteranos do Vietnã de Maya Lin e a montanha mágica de James Turell, os enfeites de praças públicas de Ellsworth Kelly e Serra, as projeções em vídeo gigantes e cafonas de criaturas flamejantes de Bill Viola, as intermináveis superfícies de papel de parede abstrato das telas de Gerhard Richter (que não chegam a alcançar a ansiedade dilatada de seu compatriota Kiefer), para citar apenas alguns -, são todos gestos artísticos românticos em grande escala animados pelo 

encenada dado por Klein) atingiu um efeito Wagner de alta densidade, mesmo sem uma escala avantajada. Tanto quanto seus objetos de arte, propriamente, era sua cuidadosamente fabricada persona como místico xamã, uma espécie de Odir Teutônico oferecendo cura e redenção por meio da arte - isso sem contar o portentoso romantismo de suas performances ritualísticas - que cheirava a efeito Wagner. Tanto Klein quanto Beuys compreendiam como a noção da escala ampliada podia ser alcançada mais facilmente pela manipulação da mídia do que pela produção de ícones gigantescos. Imagens do artista-empresário, devidamente trajado, rodeado por hordas de acólitos e nuvens de misticismo, cresciam e se transitavam sem dificuldade pela mídia.

Evidentemente, a arte grandiosa remonta ao período Madalenense e pode ser encontrada em muitos momentos subsequentes. Nesse sentido, a arte marcada pelo efeito Wagner apenas assume seu posto ao lado de todo e cada momento da arte oficial e é insignificante se comparado a esses períodos obcecados por monumentos, à exemplo do Egito Faraônico. Como em toda arte oficial, o componente do encanto e do alto custo, ou mesmo o encanto causado pelo custo, é incorporado, requisitado e alcançado pela grandiosidade da escala. E, como em grande parte da grandiosa arte oficial do passado, o que se observa nos trabalhos atuais marcados pelo efeito Wagner é, principalmente, um estilo tardio, uma estética virtualmente esgotada. Ao final do século XX, o mais sangrento já registrado, a própria ideia do monumental carrega um aroma tênue do obsceno.

Se o efeito Wagner pode ser periodizado no nosso tempo, então é possível afirmar que ele começou com Pollock. Durante os anos 1960, a única iniciativa cuja intenção era criar ícones monumentais que não acabou caindo no efeito Wagner foi a de Claes Oldenburg. Estaria esse artista profético, talvez o mais inteligente de nossa era, construindo cavalos de Tróia todo o tempo? A ironia fácil e automática encontrada em muito da arte pop é desprovida da combinação de páthos e deboche tão firmemente articulada no trabalho inicial de Oldenburg - uma obra reconhecidamente enfraquecida, mais tarde, sob as duas rubricas que a caracterizariam como uma iniciativa embalada e cooperativa. $\mathrm{O}$ único antecedente dos seus colossais objetos públicos do início de carreira, instalados em praças e outros espaços comuns, pode ser encontrado em Los Caprichos, de Goya. Os gigantes emblemas de Oldenburg não monumentalizam a imbecilidade fetichizante do capitalismo de consumo tanto quanto sua atrapalhada lógica e seus valores sem sentido, 
ARS constituídos pelo orgulho e pela abjeção. A perspectiva hobbesiana de ano 15 Oldenburg alegoriza a perversão e o fracasso da própria noção do públi-

n. 31 co em nosso tempo. Seus espaços distópicos são precisamente o oposto daqueles outros, obsequiosos, que emanam o efeito Wagner e que tão frequentemente colocam em destaque uma episteme da forma a fim de disfarçar os valores promovidos.

Os espaços utópicos do modernismo, que uniam o empírico e o transcendente dentro da marcha histórica progressiva dos ícones abstratos, desapareceram. Os atordoados e esquizofrênicos espaços bricolados da pós-modernidade, organizados a partir da revolução frenética e histérica de imagens em pastiche, se desmancham nos espasmos irregulares dos seus inconsequentes últimos suspiros.

No entanto, entre a heterogeneidade estilística dessas gigantescas obras de arte que partilham do efeito Wagner, uma arte oficial tem se coagulado ao longo dos anos, alegorizando um espaço de dominação que alude a um tipo peculiar de redenção. Um espaço escuro e triunfal, conectando as fantasias de uma classe predominantemente invisível a enormes ícones apresentados como gestos em direção a uma (falsa?) arte pública. Aqui reside uma estética fenomênica formulando e redefinindo o entretenimento como encantamento. O ideal, nesse caso, é uma espécie de lugar quase-público como afirmação imperante. Imponentes espaços de renúncia deleitosa e sedução do desejo, onde cada gesto político de resistência imaginável evapora, onde a própria ideia da crítica é expurgada em face do iminente ídolo. Uma espécie de apogeu do efeito Wagner foi sem dúvida alcançado com o Monumento de Lin aos Veteranos do Vietnã, em Washinton, D.C. Exibindo uma acentuada forma gestáltica retirada das convenções do minimalismo e da Land Art, o muro de nomes feito de granito preto funciona como uma cortina encobrindo a criminalidade governamental. A criticalidade evapora nesse minucioso teatro que coloca em destaque o luto particular, propondo-se a curar uma ferida nacional que deveria ser mantida aberta. Aqui, a arte pública alcança seu modo mais insidioso e perverso.

Talvez o efeito Wagner tenha atuado de forma pouco teorizada mais ou menos por meio século, apresentando, por meio de suas formas imensas, uma alegoria das ambições da classe dominante em suas dimensões exclusivas, monumentais e endinheiradas. Uma alegoria ainda mais enfatizada pelo empirismo de um elusivo e atordoante formalismo - um espaço retorcido, elíptico, no qual o poder celebrado elude identificação enquanto exige submissão. E quando se considera o que formas tão grandiosas são capazes de produzir, deveríamos nos esquecer de Albert Speer? 
W. J. T. Mitchell observou que o fenômeno que ele chama de dinomania tende a reaparecer periodicamente na cultura em períodos de prosperidade material. Ele enxerga o dinossauro como um ícone cultural mítico e ambivalente, que promove tanto a agonia da extinção quanto uma celebração do poder predatório do capitalismo ${ }^{13}$. Mitchell pontua que a instituição dos grandes museus americanos tem início com a construção, por Charles Wilson Peale, de um espaço para apresentar publicamente a ossada de um mastodonte, sendo esse "monstro" do museu sua principal atração (o termo monstro é duplamente adequado, conforme revela a investigação de suas origens no latim: monstrum denota tanto monstruosidade quanto advertência; monstrare significa "mostrar"). A recente aquisição do Museu Field de História Natural de Chicago, no valor de 8,36 milhões de dólares, de um fóssil de Tyrannosaurus rex, apelidado Sue, fecha o círculo de volta a Peale. Mais do que isso, contudo, Sue é puro efeito Wagner: um enigma de origens banhado pelo encanto misterioso com tempos remotos; as capacidades de Tânatos, de suas presas de vinte centímetros e de seu gigantesco tamanho, que induzem a um calafrio diante do sublime, junto com a secreta e necrosada satisfação de saber que o animal está morto, extinto; e, sobretudo, a raridade desse fetiche garantida pelas imaculadas profundezas do monetário. Conforme destacou Mitchell, os gigantescos ícones que os museus de arte colecionam não estão desvinculados desses massivos ossos fossilizados do museu de história natural.

O museu de arte contemporânea do presente celebra, mais do que nunca, a crescente tendência da moda e do kitsch. Exposições como a recente "The Art of the Motorcycle", no Guggenheim de Nova Iorque, configuram-se como tentativas de propiciar, perpetuar e celebrar a democracia do fetiche kitsch, reafirmando mais uma vez que o baixo ocupa o lugar mais alto a que se pode querer chegar. Ainda assim, o efeito Wagner é ocasionalmente deslocado para se tornar um meio de atingir o elevado. Ícones sagrados são necessários hoje em dia, apenas não com tanta frequência. Contudo, seja pelo kitsch ou pelo efeito Wagner, apenas a agitação do evento cultural como espetáculo garante um caminho.

O museu de arte atual se afastou, sem dúvida, de seu papel como uma instituição meramente aberta ao público para o de uma que esteja ativamente a serviço do público. Ou seja, deslocou sua raison d'être ou posição cultural estratégica daquela que é marcada por uma coerência interna, na qual sua responsabilidade reside em compartilhar seu conhecimento elitista com um público, para uma preocupação tática com
13. Cf. MITCHELL, William. The last dinosaur book: the life and times of a cultural icon. Chicago: University of Chicago Press, 1998. 
os fatores externos dos eventos encenados que serão vendidos ao públi-

ano 15

n. 31

14. HARRIS, Neil. Cultural excursions: marketing appetites and cultural tastes in modern America. Chicago: University of Chicago Press, 1990, p. 18.

15. "Carioca dancing" faz referência à coreografia executada por Fred Astaire e Ginger Rogers no filme Flying down to Rio, de 1933.

Visto que não foi encontrado um correspondente para esta expressão na língua portuguesa, possivelmente porque essa espécie de dança de salão não parece constituir uma manifestação cultural brasileira propriamente, nem uma modalidade de dança consolidada, e sim uma elaboração criada no filme a partir de vagas alusões a ritmos musicais típicos do Brasil, optou-se por mantê-la conforme utilizado na versão original (N.T.). co. Sem dúvida, é possível que os museus estejam apenas retornando ao papel que eles desempenhavam na América pré-Guerra Civil, quando, conforme descreve Neil Harris,

a alta cultura ainda não havia sido separada da cultura popular. Museus como o Barnum's, em Nova Iorque, o Boston Museum, de Kimball, o Museu criado por Peale, na Filadélfia, ou o Western Museum, em Cincinnati, reuniam todo tipo de bizarrices - flechas indígenas, ossos de dinossauros e porcos de duas cabeças, apresentados junto a moldes de esculturas gregas e pinturas de Gilbert Stuart e Thomas Scully. ${ }^{14}$

Atualmente, alguns museus enviam suas equipes para serem treinadas pela Disney. Promover o entretenimento se torna a ordem do dia. $\mathrm{O}$ visitante é servido, recebe uma programação e fones de ouvido para o evento em exibição. Carioca dancing ${ }^{15}$, guitarristas, desfiles de moda e eventos recreativos noturnos são anunciados, e a diversão se estende por toda parte, até à loja do museu. O museu se metamorfoseia em um centro comercial da cultura. Pelo exorbitante valor de entrada, uma espécie de Gesamtkunstwerk da experiência estética é proporcionada. Curadores se tornam artistas que encenam eventos com cenografias. A experiência do museu garante a continuidade da estetização do lifestyle de cada um. Ocasionalmente, no entanto, o objeto de arte consegue, dado um volume suficiente de efeito Wagner, competir com o ruído promocional do entorno. Esses objetos dos museus capazes de gerar efeito Wagner suficientemente fornecem, simultaneamente, fetiches estéticos fenomênicos que são, também, ídolos culturais transcendentes e, no mais das vezes, nacionalistas, e que, em muitos casos, também impressionam como totens assegurados pragmaticamente por massivos cifrões e por linhagens históricas - tudo isso entregue na embalagem de um maravilhoso evento.

O Guggenheim Bilbao de Frank Gehry, templo do e para o gigantesco, oferece o mais recente e atual palco para os ataques estéticos do impressionantemente grande. Até mesmo dinossauros se perderiam nesses espaços que mais lembram galpões para dirigíveis. Nesse caso, pelo menos, o que se tem é a arquitetura do efeito Wagner especialmente construída para a arte do efeito Wagner.

Se o esforço inicial de Gehry na residência de Santa Mônica não chega nem perto da declaração de Fredric Jameson de que ele se constitui como uma tentativa de repensar os problemas cognitivos e espaciais da fusão dos espaços privado e corporativo - "os dois atributos antitéticos e 
224

incomensuráveis (...) do espaço abstrato americano"16 -, os vastos espaços processionais de Bilbao são seguramente uma reflexão sobre a resolução do conflito em favor do corporativo. Se a corporação multinacional atual é a apoteose do gigantesco, até a construção de Bilbao não existia alegoria cultural apropriada para ele. Antes de Bilbao, não havia metáforas espaciais concretas para os invisíveis, ciberespaciais elos entre os ativos extensivos e disparatados e os elegantes controles que caracterizam o corporativo, vínculos esses manifestados como fluxos de informação entre entidades separadas, mas conectadas. No entanto, nesse museu basco, o desdobramento processional de espaços nobres, "mutáveis, polimorfos, heterogêneos"17 sem dúvida alegoriza o espírito da gigantesca corporação multinacional em todas suas expansíveis, conglomeradas e incrivelmente multifacetadas capacidades, efeito Wagner realizado com um esplendor que em muito ultrapassa os ícones avolumados que esse museu abriga. Mas, afinal, Gehry uma vez observou que os artistas queriam espaços impressionantes onde pudessem apresentar suas "nobres criações”.

Foi necessário meio século para reificar a forma de um impulso estético maior - talvez como parte daquela marcha mais ampla em direção à totalização das objetificações conduzida pelas noções weberianas, racionalizadas, administradas e burocráticas da alienação e do progresso na modernidade. Até agora, a fetichização da forma abstrata iconofóbica, da qual a arte minimalista foi a última grande expressão, tem perdurado por um século. Mas a forma nunca carregou o peso que deveria suportar embora as ideologias das quais tenha sido incumbida pesassem toneladas.

Se a estética é um aspecto tão central, atraente e misterioso nas nossas vidas quanto o sexo, não deveria ser tão surpreendente que ambos vendam tão bem. As estratégias da arte do efeito Wagner surgem como tentativas de se fazer ouvir contra o ruído comercializado (e também em paralelo a ele, evidentemente) do ambiente estetizado, dentro do qual o museu se tornou nada além de uma concorrente instituição de entretenimento. Contudo, no século XX, muito mais do que apenas o estético foi reificado e fetichizado, corrompido e explorado. E a cultura do capitalismo tardio, que se prepara para atacar este milênio, há muito ultrapassou o ponto em que ideias de contenção, e muito menos de reintegração, ainda são concebíveis.

Robert Morris é um artista que escreve esporadicamente. Em 1994, publicou sua coleção de ensaios, Continuous Project, Altered Daily. Sua contribuição mais recente à Critical Inquiry é “Cézanne's Mountains” (Primavera, 1998).

\section{Robert Morris}

Tamanho é documento.

16. JAMESON, Fredric. Postmodernism: or, the cultural logic of late capitalism. Durham:

Duke University Press, 1992, p. 128. Jameson identifica a justaposição do "cubo-desmantelado" à grade de ferro e à placa de metal corrugado na casa de Gehry, em Santa Mônica, como emblemática desse diálogo. (p. 127-133, na tradução). Cf. também: Idem. Pós-modernismo: a lógica cultural do capitalismo tardio. Tradução Maria Elisa Cevasco. São Paulo: Ática, 1996. (Série Temas, v. 41).

17. MUSCHAMP, Herbert. Regent and king in a procession of new forms. New York Times, New York, 29 nov. 1998. Disponível em: <https://goo.gl/TSvHY8>. Acesso em: 22 nov. 2017. Neste trecho, Muschamp exalta as maravilhas formais dos espaços e permanece em silêncio sobre qualquer leitura iconológica ou ideológica da arquitetura.

Artigo recebido em 6 de novembro de 2017 e aceito em 6 de novembro de 2017. 